SUPPLEMENTARY INFORMATION

2

\title{
MMF of Models and Surface Observations
}

As the multi-model studies have shown, significant biases in deposition remain even when using ensembles. While efforts continue towards reducing these biases, approaches that use available observations to adjust model output, rather than just evaluate it, can provide improved estimates of deposition for use by earth and eco-system scientists and for policy purposes. The availability of global satellite observations also provides an opportunity for regions that lack observations and can improve the MMF-GTAD

11 capabilities.

12 In the U.S. ${ }^{1}, \mathrm{Canada}^{2}$, and $\mathrm{Sweden}^{3}$, regional-scale MMF approaches have already been

13 developed. These approaches have been generalized to the conceptual methodology

14 shown in Figure 2. The overall concept of MMF involves bias correcting CTM-computed variables using observational data sets to create fused deposition maps. In this example, for wet deposition, the concentrations of ions in precipitation from the model and the observations are fused to create maps of concentrations. Similarly, the modeled and measured precipitation depths are also fused. These two fused products are then combined to provide fluxes of wet deposition for the species that were included in the observational data. The wet deposition of additional chemicals (e.g., organic nitrogen) that are not measured is derived solely from the CTM and is added to the final estimate of MMF wet deposition. The calculations for dry deposition are done in a slightly different but related manner: the species surface concentrations, both simulated and observed, are first fused after which the modelled dry deposition velocities are applied to produce dry deposition flux maps. While not included in current MMF approaches, the generalized method in Figure 2 recognizes the potential for use of satellite-derived concentrations for wet and dry deposition. The CTM model provides dry deposition velocities for measured species, as well as dry deposition flux values of unmeasured (or sparsely-measured) species such as nitrate radicals $\left(\mathrm{NO}_{3}\right)$, nitric anhydride $\left(\mathrm{N}_{2} \mathrm{O}_{5}\right)$, nitrous acid (HONO), and organic N. Depending on the CTM used, deposition velocities may be available as gridaveraged or land-cover specific values ${ }^{4}$. Land-cover specific values may be important for estimating deposition to sensitive ecosystems. These could then be applied to the concentration fields to calculate both grid-averaged and land-cover-specific dry deposition fluxes. Once dry deposition and wet deposition have been calculated, they can be summed to produce maps of total deposition as shown in Figure 3.

\section{Global MMF Using Satellite Observations}

The MMF of surface observations and models is a promising step forward to provide deposition estimates in regions with sufficient model and observational capacity ${ }^{5-8}$. However, with the exception of North America and Europe (and recently also East Asia), surface-observation based MMF techniques are hampered by a lack of observations in large parts of the world. To produce global measurement-model fusion products for

44 deposition, several components of the methodology need to be explored and developed. 
45 The methods used to produce the regional maps should be evaluated for global models

46 and data sets with their performance compared using cross-validation. Some fusion techniques may be more appropriate than others for regions where data are sparse, or to account for the lower spatial resolution of global models. For instance, due to in-situ measurement data sparsity, the inclusion of broad-scale satellite observations will be a major step forward for the future global mapping.

Spatially continuous satellite-derived estimates of surface concentrations of some directly retrieved constituents (e.g., $\mathrm{NO}_{2}, \mathrm{SO}_{2}, \mathrm{NH}_{3}$ ) may be combined with inferential dry deposition models to calculate dry deposition fluxes. Satellite-based surface concentration estimates have been derived using geophysical modeling approaches ${ }^{5-11}$, or using empirical/statistical relationships with in-situ observations ${ }^{12}$. Deposition estimates of constituents not directly observed by satellite have also been estimated from satellite observations using statistical relationships between the observed and modelled ${ }^{13}$ constituents and several processes of interest, e.g., wet $\mathrm{NO}_{3}{ }^{-}$or $\mathrm{NH}_{4}{ }^{+}$deposition ${ }^{14-15}$. Alternatively, satellite observations can be used in model inversion experiments to improve emission inventories. These updated surface emissions may then provide better constraints on the ultimate deposition predicted by chemical transport models ${ }^{16}$. The latter approach has the benefit of providing improvements in predictions of chemical species that are not directly observed by satellite but which are related by chemistry (e.g., improving $\mathrm{NO}_{\mathrm{x}}$ emissions estimates to simultaneously improve modeled deposition estimates of $\mathrm{NO}_{2}, \mathrm{HNO}_{3}$, acylperoxy nitrates, particulate $\mathrm{NO}_{3}^{-}$, and even $\mathrm{O}_{3}$ ). A review of some relevant methods and current limitations in deriving surface concentration and deposition estimates from satellite observations can be found in Liu et al. $2020 b^{17}$. Direct assimilation of satellite observations of atmospheric composition in atmospheric chemical forecast models ${ }^{18}$ also has the potential to provide improvements into near-real time deposition predictions, but this opportunity has thus far not been explored for deposition.

Satellite observations are also useful in constraining precipitation depths. Over Southeast Asia, models in MICS-Asia phase III had difficulty capturing wet deposition during dry and wet seasons. By adjusting the simulated precipitation using TRMM measurements, both the simulated wet deposition amount and its seasonal pattern were improved ${ }^{19}$. Existing global analysis products for precipitation, such as those from the Global Precipitation Climatology Centre (https://www.dwd.de/EN/ourservices/gpcc/gpcc.html, last access on January 13, 2021), could be used as part of the wet deposition methodology, but the advantage of improved precipitation fields should be weighed against the impact of decoupling those fields from the ion concentrations in that precipitation. To address these questions, a pilot study using one year of global CTM output (or an ensemble) and a global precipitation data set will first need to be undertaken before an operational system is implemented. 
More information about MMF methods can be found in the World Meteorological Organization Global Atmosphere Watch Measurement-Model Fusion for Global Total Atmospheric Deposition Initiative Implementation Plan 2021-202520.

HTAP. The Task Force on Hemispheric Transport of Air Pollution ${ }^{21}$ (http://htap.org/, last access on February 22, 2021) aims at addressing policy-relevant science questions regarding the intercontinental transport of air pollutants. The $2^{\text {nd }}$ phase of HTAP (HTAP II) was initiated in 2012, with the participation of more than 20 modelling groups for a series of simulations covering years 2008-2010 ${ }^{21}$. Tan et al. (2018) ${ }^{22}$ assessed the performance of HTAP II models in simulating wet deposition of nitrate $\left(\mathrm{NO}_{3}^{-}\right)$, ammonium $\left(\mathrm{NH}_{4}{ }^{+}\right)$and sulfate $\left(\mathrm{SO}_{4}{ }^{2-}\right)$ with observations from the National Atmospheric Deposition Program (NADP, http://nadp.slh.wisc.edu/, last access on January 13, 2021), European Monitoring and Evaluation Programme (EMEP, http://emep.int/, last access on March 20, 2021) and Acid Deposition Monitoring Network in East Asia (EANET, http://www.eanet.asia/). Wet $\mathrm{SO}_{4}{ }^{2-}$ deposition was well modeled in the US and Europe,

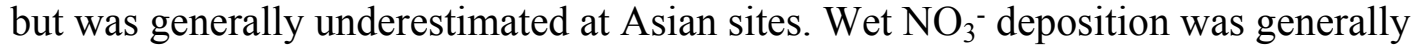
overestimated in the US, and in general agreement with observations in Europe and Asia. Modeled wet $\mathrm{NH}_{4}{ }^{+}$deposition was in good agreement with observations in the US and Europe, but was underestimated in Asia. Compared to the earlier HTAP Phase $\mathrm{I}^{23}$ values, the model accuracies for predicting wet deposition in HTAP II improved significantly in Europe and East Asia ${ }^{13}$.

UNECE TFMM and AQMEII. The United Nations Economic Commission for Europe (UNECE) Task Force on Measurements and Modelling (TFMM) promotes better synergies between monitoring and modelling activities under the regional EMEP cooperative programme. The Air Quality Modelling Evaluation International Initiative (AQMEII) investigates air quality modelling issues over Europe and North America ${ }^{21}$ (https://aqmeii.jrc.ec.europa.eu/). The $3^{\text {rd }}$ phase of AQMEII (AQMEII 3) was conducted in coordination with HTAP II with inputs from regional modelling groups in North

116 Vivanco et al. (2018) $)^{23}$ assessed the performance for oxidized nitrogen (ON), reduced 117 nitrogen (RN) and sulfur (S) of 14 models from AQMEII 3 and EURODELTA-Trends 118 (EDT $)^{25}$ projects using observations from 88 EMEP monitoring sites covering Europe. 119 The model ensemble demonstrated acceptable performance for total wet $\mathrm{NO}_{3}{ }^{-}$deposition (particulate $\mathrm{NO}_{3}{ }^{-}+$gaseous nitric acid $\left(\mathrm{HNO}_{3}\right)$ ) and total wet $\mathrm{NH}_{4}{ }^{+}$deposition (particulate $\mathrm{NH}_{4}{ }^{+}+$gaseous $\mathrm{NH}_{3}$ ). However, the model accuracies for simulating gaseous species $\left(\mathrm{HNO}_{3}\right.$ and $\left.\mathrm{NH}_{3}\right)$ were less satisfactory than for particles, and the very limited number of observations of gaseous species and the short lifetimes of these components prevented robust conclusions. A tendency to underestimate $\mathrm{S}$ deposition was noted. Theobald et al. (2019) ${ }^{26}$ compared the performance of six European CTMs with observations, showing that the model biases of annual wet deposition of $\mathrm{N}$ and $\mathrm{S}$ species 128 were $30-40 \%$ for most models, and the biases were fairly persistent over the period 19902010. 
129 MICS-Asia. The Model Inter-Comparison Study for Asia (MICS-Asia) has been

130 conducted to improve the modeling of air quality in that region. In MICS-Asia Phase III,

13114 modelling groups from the USA and East Asia participated in simulating the air

132 quality and acid deposition for the entire year of 2010. The number of EANET

133 observation sites increased from 37 to 54 with good coverage of Southeast Asian

134 countries. Itahashi et al. (2020) ${ }^{27}$ evaluated the Multi-Model Mean (MMM) performance

135 of 9 models for the wet deposition of $\mathrm{S}$ ( sum of $\mathrm{SO}_{4}{ }^{2-}, \mathrm{SO}_{2}$ and sulfuric acid $\left(\mathrm{H}_{2} \mathrm{SO}_{4}\right)$ ),

136 oxidized nitrogen $\left(\mathrm{ON}: \mathrm{NO}_{3}{ }^{-}, \mathrm{NO}, \mathrm{NO}_{2}\right.$ and $\left.\mathrm{HNO}_{3}\right)$ and reduced nitrogen ( $\mathrm{RN}: \mathrm{NH}_{4}{ }^{+}$and

$137 \mathrm{NH}_{3}$ ). The models generally captured observed wet deposition, but underestimated $\mathrm{S}$ and

$138 \mathrm{NH}_{4}{ }^{+}$deposition. Also, there was large variability amongst models for $\mathrm{ON}$ deposition. Ge

139 et al. $(2020)^{28}$ utilized available observation network over China, and pointed out that RN

140 wet deposition was underestimated by all models across China. Tan et al. (2020) ${ }^{29}$ found

141 that models generally failed to reproduce the high rates of wet $\mathrm{NO}_{3}{ }^{-}$and $\mathrm{NH}_{4}{ }^{+}$deposition

142 observed in Southeast Asia, especially in Malaysia and the Philippines.

143 ACCMIP/CMIP AR5. The Atmospheric Chemistry and Climate Model Intercomparison 144 Project (ACCMIP) has conducted a series of modelling studies for the period between

1451850 and 2100 to understand the long-term changes of atmospheric composition and its

146 role in driving climate change ${ }^{30}$. A total of 16 models participated with various chemical

147 schemes and horizontal and vertical resolution. A series of simulations under different

148 emission scenarios were conducted to investigate the key factors in driving the historical

149 and future climate change. Lamarque et al. $(2013)^{30}$ evaluated model performances for

150 wet deposition for 2000-2002 with observations from EMEP, NADP, Canadian Air and

151 Precipitation Monitoring Network (CAPMoN, https://www.canada.ca/en/environment-

152 climate-change/services/air-pollution/monitoring-networks-data/canadian-air-

153 precipitation.html, last access on March 20, 2021), EANET and International Network to

154 study Deposition and Atmospheric chemistry in AFrica/DEposition of Biogeochemically

155 Important Trace Species (INDAAF, http://indaaf.obs-mip.fr, last access on March 20,

156 2021). Models captured the general observed features of $\mathrm{NO}_{3}{ }^{-}$deposition, but most

157 models failed to reproduce the high deposition rates over East Asia and Europe.

158 Underestimation of $\mathrm{NH}_{4}{ }^{+}$deposition in Asia, that also partly affected the model accuracy

159 in simulating $\mathrm{NO}_{3}{ }^{-}$deposition in this region, was probably due to the use of incorrect

160 distribution of $\mathrm{NH}_{3}$ agricultural emissions in China and Mongolia. 
164 Phased improvements in global atmospheric deposition maps will be accomplished in stages (Figure S1). The first stage is to produce maps using the best available information for a particular region. In regions where MMF is already being carried out, the MMF maps will be used as they are. In other regions, model-derived maps will be used. In areas where regional multi-model ensemble estimates of atmospheric deposition are available, these will be used (as demonstrated in Figure 1). Other regions will be covered by products extracted from global multi-model ensemble output. In the next stage, this process will become more operational, and MMF expanded to more regions with increased use of improved ground-based and airborne observing systems including satellites for data assimilation. In future stages, atmospheric composition chemical reanalysis products will be utilized. Several research and operational centers are developing chemical reanalysis products by the assimilation of a large number of meteorological data sets and observations of concentration and column burdens. These products can provide global/regional MMF products that will be evaluated against current 179

180

\section{MMF approaches.}

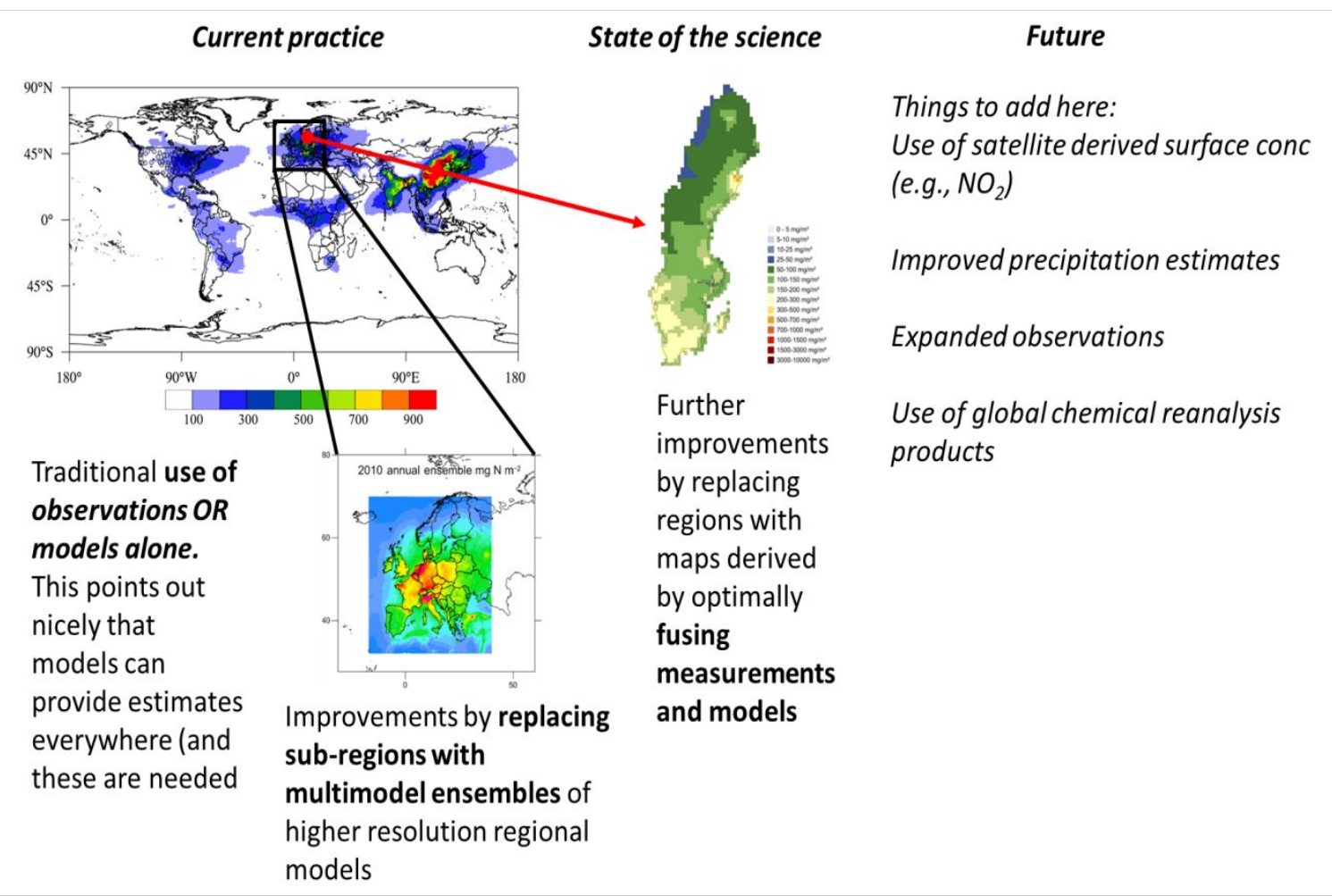

Figure S1. Planned MMF-GTAD stages

\section{REFERENCES}

(1) Schwede, D. B.; Lear, G. G.A Novel Hybrid Approach for Estimating Total Deposition in the United States. Atmos. Environ. 2014, 92, 207-220. https://doi.org/10.1016/j.atmosenv.2014.04.008. 
(2) Schwede, D.; Cole, A.; Vet, R.; Lear, G.; Canada, O. U. S.On-Going U.S.-Canada Collaboration on Nitrogen and Sulfur Deposition on Nitrogen and Sulfur

(3) Andersson, C.; Wylde, H. A.; Engardt, M.Long-Term Sulfur and Nitrogen Deposition in Sweden 1983-2013. 2018, SMHI METEOROLOGY No. 163.

(4) Schwede, D. B.; Simpson, D.; Tan, J.; Fu, J. S.; Dentener, F.; Du, E.; deVries, W.Spatial Variation of Modelled Total, Dry and Wet Nitrogen Deposition to Forests at Global Scale. Environ. Pollut. 2018, 243, 1287-1301. https://doi.org/10.1016/j.envpol.2018.09.084.

(5) Nowlan, C. R.; Martin, R.V.; Philip, S.; Lamsal, L. N.; Krotkov, N. A.; Marais, E. A.; Wang, S.; Zhang, Q.Global Dry Deposition of Nitrogen Dioxide and Sulfur Dioxide Inferred from Space-Based Measurements. Global Biogeochem. Cycles 2014, 28 (10), 1025-1043. https://doi.org/10.1002/2014GB004805.

(6) Kharol, S. K.; Shephard, M. W.; McLinden, C. A.; Zhang, L.; Sioris, C. E.; O’Brien, J. M.; Vet, R.; Cady-Pereira, K. E.; Hare, E.; Siemons, J.; Krotkov, N. A.Dry Deposition of Reactive Nitrogen From Satellite Observations of Ammonia and Nitrogen Dioxide Over North America. Geophys. Res. Lett. 2018, 45 (2), 1157-1166. https://doi.org/10.1002/2017GL075832.

(7) Liu, L.; Zhang, X.; Xu, W.; Liu, X.; Wei, J.; Wang, Z.; Yang, Y.Global Estimates of Dry Ammonia Deposition Inferred from Space-Measurements. Sci. Total Environ. 2020, 730, 139189. https://doi.org/10.1016/j.scitotenv.2020.139189.

(8) van derGraaf, S. C.; Dammers, E.; Schaap, M.; Willem Erisman, J.Technical Note: How Are NH3 Dry Deposition Estimates Affected by Combining the LOTOSEUROS Model with IASI-NH3 Satellite Observations? Atmos. Chem. Phys. 2018, 18 (17), 13173-13196. https://doi.org/10.5194/acp-18-13173-2018.

(9) Lamsal, L. N.; Martin, R.V.; vanDonkelaar, A.; Steinbacher, M.; Celarier, E. A.; Bucsela, E.; Dunlea, E. J.; Pinto, J. P.Ground-Level Nitrogen Dioxide Concentrations Inferred from the Satellite-Borne Ozone Monitoring Instrument. $J$. Geophys. Res. Atmos. 2008, 113 (16), 1-15. https://doi.org/10.1029/2007JD009235.

(10) Geddes, J. A.; Martin, R.V.; Boys, B. L.; vanDonkelaar, A.Long-Term Trends Worldwide in Ambient NO2 Concentrations Inferred from Satellite Observations. Environ. Health Perspect. 2016, 124 (3), 281-289.

https://doi.org/10.1289/ehp.1409567.

(11) Liu, L.; Zhang, X.; Wong, A. Y. H.; Xu, W.; Liu, X.; Li, Y.; Mi, H.; Lu, X.; Zhao, L.; Wang, Z.; Wu, X.Estimating Global Surface Ammonia Concentrations Inferred from Satellite Retrievals. Atmos. Chem. Phys. 2019, 19, 12051-12-66. https://doi.org/10.5194/acp-19-12051-2019. 
(12) Cheng, M.; Jiang, H.; Guo, Z.; Zhang, X.; Lu, X.Estimating NO2 Dry Deposition Using Satellite Data in Eastern China. Int. J. Remote Sens. 2013, 34 (7), 25482565. https://doi.org/10.1080/01431161.2012.747019.

(13) Liu, L.; Yang, Y.; Xi, R.; Zhang, X.; Xu, W.; Liu, X.; Li, Y.; Liu, P.; Wang, Z.Global Wet Reduced Nitrogen Deposition Derived from Combining Satellite Measurements with Output from a Chemistry Transport Model. J. Geophys. Res. Atmos. 2020, No. December. https://doi.org/10.1029/2020jd033977.

(14) Liu, L.; Zhang, X.; Xu, W.; Liu, X.; Lu, X.; Chen, D.; Zhang, X.; Wang, S.; Zhang, W.Estimation of Monthly Bulk Nitrate Deposition in China Based on Satellite NO2 Measurement by the Ozone Monitoring Instrument. Remote Sens. Environ. 2017, 199, 93-106. https://doi.org/10.1016/j.rse.2017.07.005.

(15) Jia, Y.; Yu, G.; Gao, Y.; He, N.; Wang, Q.; Jiao, C.; Zuo, Y.Global Inorganic Nitrogen Dry Deposition Inferred from Ground- and Space-Based Measurements. Sci. Rep. 2016, 6, 1-11. https://doi.org/10.1038/srep19810.

(16) Geddes, J. A.; Martin, R.V.Global Deposition of Total Reactive Nitrogen Oxides From. Atmos. Chem. Phys. 2017, 17, 10071-10091. https://doi.org/doi.org/10.5194/acp-17-10071-2017.

(17) Liu, L.; Zhang, X.; Xu, W.; Liu, X.; Lu, X.; Wei, J.; Li, Y.; Yang, Y.; Wang, Z.; Wong, A.Reviewing Global Estimates of Surface Reactive Nitrogen Concentration and Deposition Using Satellite Observation. Atmos. Chem. Phys. 2020, 2, 1-44. https://doi.org/10.5194/acp-2020-91.

(18) Inness, A.; Blechschmidt, A. M.; Bouarar, I.; Chabrillat, S.; Crepulja, M.; Engelen, R. J.; Eskes, H.; Flemming, J.; Gaudel, A.; Hendrick, F.; Huijnen, V.; Jones, L.; Kapsomenakis, J.; Katragkou, E.; Keppens, A.; Langerock, B.; DeMazière, M.; Melas, D.; Parrington, M.; Peuch, V. H.; Razinger, M.; Richter, A.; Schultz, M. G.; Suttie, M.; Thouret, V.; Vrekoussis, M.; Wagner, A.; Zerefos, C.Data Assimilation of Satellite-Retrieved Ozone, Carbon Monoxide and Nitrogen Dioxide with ECMWF's Composition-IFS. Atmos. Chem. Phys. 2015, 15 (9), 5275-5303. https://doi.org/10.5194/acp-15-5275-2015.

(19) Schneider, U.; Ziese, M.; Meyer-christoffer, A.; Finger, P.; Rustemeier, E.The New Portfolio of Global Precipitation Data Products of the Global Precipitation Climatology Centre Suitable to Assess and Quantify the Global Water Cycle and Resources. Proc. IAHS 2016, 374, 29-34. https://doi.org/10.5194/piahs-374-29$\underline{2016}$

(20) World Meteorological Organization Global Atmosphere Watch MeasurementModel Fusion for Global Total Atmospheric Deposition Initiative Implementation Plan 2021-2025. June 2021, GAW Report No. 269 
(21) Galmarini, S.; Koffi, B.; Solazzo, E.; Keating, T.; Hogrefe, C.; Schulz, M.; Benedictow, A.; Griesfeller, J. J.; Janssens-Maenhout, G.; Carmichael, G.; Fu, J.; Dentener, F.Technical Note: Coordination and Harmonization of the Multi- Scale, Multi-Model Activities HTAP2, AQMEII3, and MICS-Asia3: Simulations, Emission Inventories, Boundary Conditions, and Model Output Formats. Atmos. Chem. Phys. 2017, 17, 1543-1555. https://doi.org/10.5194/acp-17-1543-2017.

(22) Tan, J.; Fu, J. S.; Dentener, F.; Emmons, L.Multi-Model Study of HTAP II on Sulfur and Nitrogen Deposition. Atmos. Chem. Phys. 2018, 18, 6847-6866.

(23) Vet, R.; Artz, R. S.; Carou, S.; Shaw, M.; Ro, C.; Aas, W.; Baker, A.; Bowersox, V. C.; Dentener, F.; Galy-lacaux, C.; Hou, A.; Pienaar, J. J.; Gillett, R.; Forti, M. C.; Gromov, S.; Hara, H.; Khodzher, T.; Mahowald, N. M.; Nickovic, S.; Rao, P. S. P.; Reid, N. W.A Global Assessment of Precipitation Chemistry and Deposition of Sulfur, Nitrogen, Sea Salt, Base Cations, Organic Acids, Acidity and PH, and Phosphorus. Atmos. Environ. 2014, 93, 3-100. https://doi.org/10.1016/j.atmosenv.2013.10.060.

(24) Vivanco, M. G.; Theobald, M. R.; García-Gómez, H.; Garrido, J. L.; Prank, M.; Aas, W.; Adani, M.; Alyuz, U.; Andersson, C.; Bellasio, R.; Bessagnet, B.; Bianconi, R.; Bieser, J.; Brandt, J.; Briganti, G.; Cappelletti, A.; Curci, G.; Christensen, J. H.; Collette, A.; Couvidat, F.; Cuvelier, C.; D’Isidoro, M.; Flemming, J.; Fraser, A.; Geels, C.; Hansen, K. M.; Hogrefe, C.; Im, U.; Jorba, O.; Kitwiroon, N.; Manders, A.; Mircea, M.; Otero, N.; Pay, M.-T.; Pozzoli, L.; Solazzo, E.; Tsyro, S.; Unal, A.; Wind, P.; Galmarini, S.; Pozzer, A.Modeled Deposition of Nitrogen and Sulfur in Europe Estimated by 14 Air Quality Model Systems: Evaluation, Effects of Changes in Emissions and Implications for Habitat Protection. Atmos Chem Phys 2018, 18 (14), 10199-10218. https://doi.org/10.5194/acp-18-10199-2018.Modeled.

(25) Colette, A.; Andersson, C.; Manders, A.; Mar, K.; Mircea, M.; Pay, M.; Raffort, V.; Tsyro, S.; Cuvelier, C.; Adani, M.; Bessagnet, B.; Bergström, R.; Briganti, G.; Butler, T.; Cappelletti, A.; Couvidat, F.; Isidoro, M. D.; Doumbia, T.EURODELTA-Trends, a Multi-Model Experiment of Air Quality Hindcast in Europe over 1990-2010. Geosci. Model Dev. 2017, No. i, 3255-3276.

(26) Theobald, M. R.; Vivanco, M. G.; Aas, W.; Andersson, C.; Ciarelli, G.; Couvidat, F.; Cuvelier, K.; Manders, A.; Mircea, M.; Pay, M.; Tsyro, S.; Adani, M.An Evaluation of European Nitrogen and Sulfur Wet Deposition and Their Trends Estimated by Six Chemistry Transport Models for the Period 1990-2010. Atmos. Chem. Phys. 2019, 379-405.

(27) Itahashi, S.; Ge, B.; Sato, K.; Fu, J. S.; Wang, X.; Yamaji, K.MICS-Asia III: Overview of Model Intercomparison and Evaluation of Acid Deposition over Asia. Atmos. Chem. Phys. 2020, 2667-2693. 
(28) Ge, B.; Itahashi, S.; Sato, K.; Xu, D.; Wang, J.; Fan, F.; Tan, Q.; Fu, J. S.Model Inter-Comparison Study for Asia (MICS-Asia) Phase III: Multimodel Comparison of Reactive Nitrogen Deposition over China. Atmos. Chem. Phys. 2020, 20 , 10587-10610.

(29) Tan, J.; Fu, J. S.; Carmichael, G. R.; Itahashi, S.; Tao, Z.; Huang, K.; Dong, X.Why Do Models Perform Differently on Particulate Matter over East Asia? A Multi-Model Intercomparison Study for MICS-Asia III. Atmos. Chem. Phys 2020, 20, 7393-7410.

(30) Lamarque, J.-F.; Dentener, F.; Mcconnell, J.; Ro, C.; Shaw, M.; Vet, R.; Bergmann, D.Multi-Model Mean Nitrogen and Sulfur Deposition from the Atmospheric Chemistry and Climate Model Intercomparison Project ( ACCMIP): Evaluation of Historical and Projected Future Changes. Atmos. Chem. Phys. 2013, 13, 7997-8018. https://doi.org/10.5194/acp-13-7997-2013. 